\title{
“O projeto já chegou até nós pronto e não podemos mudar muita coisa!": a metodologia participativa do PAC e a atuação das lideranças comunitárias no projeto de (re)urbanização de uma favela do Rio de Janeiro
}

"The project has already come to us ready and we can not change much!": the participatory methodology of the PAC and the role of community leaders in the (re) urbanization project of a favela in Rio de Janeiro

Juliana Blasi Cunha*

* Universidade Estadual do Norte Fluminense - Campos dos Goytacazes, RJ, Brasil Em pós-doutoramento (bolsista PNPD/Capes) jblasicunha@gmail.com 


\title{
Resumo
}

Ao apresentar uma breve contextualização sobre as políticas habitacionais no país, o artigo, inicialmente, situa historicamente o projeto de (re)urbanização de favelas do PAC. Mais especificamente, através da etnografia, o texto busca descrever a metodologia participativa proposta pelos agentes da "equipe social do PAC" e a forma como tal metodologia é posta em prática, ressaltando os desafios e limitações dessa metodologia. O trabalho busca ainda analisar como moradores e lideranças se utilizam dos "meios oficiais" que lhes foram disponibilizados pelo PAC, mas também alguns mecanismos acionados por eles em suas práticas para expor demandas e assegurar objetivos diante desse processo.

Palavras-chave: políticas habitacionais; favela; gestão participativa; associativismo.

\begin{abstract}
In presenting a brief contextualization on housing policies in the country, the article initially situates the PAC (re) urbanization project. More specifically, through ethnography, the text seeks to describe the participatory methodology proposed by the agents of the "PAC social team" and how such methodology is put into practice, highlighting aspects of an elaborated top-down policy. The paper also seeks to analyze how residents and leaders use the "official means" that were made available to them by the PAC, but also some mechanisms that they have implemented in their practices to expose demands and ensure objectives in this process.
\end{abstract}

Keywords: housing policies; favela; participatory management; associativism. 


\section{Introdução}

No segundo andar de um dos prédios construídos pelo Programa de Aceleração do Crescimento (PAC) na favela do Cantagalo, Zona Sul do Rio de Janeiro, mora Dona Márcia. ${ }^{1}$ Ela é nascida no Pavão-Pavãozinho, favela vizinha, onde morou por 37 anos, até que, em 2011, fora "remanejada" pelo PAC para esse prédio no Cantagalo. Em tal prédio, em um mesmo andar, passaram a viver pessoas dessas duas favelas. As favelas em questão são vizinhas, porém possuem histórias distintas de formação e ocupação, perpassadas por recorrentes disputas e rivalidades entre seus moradores. $O$ fato é que não existe um sentimento de pertença dos moradores ao que o poder público chama de "Complexo Pavão-Pavãozinho-Cantagalo", mas sim a uma ou a outra favela, destacando que não se trata de um todo uniforme.

O apartamento de Dona Márcia fica no final do seu corredor e, antes da sua porta, ela instalou uma grade de ferro. Tal grade está sempre fechada, estando ela em casa ou não. Em nossas conversas iniciais, Dona Márcia dizia não ter problemas com a nova vizinhança, mas, após algum tempo de convívio, relatou alguns conflitos cotidianos com os moradores do Cantagalo. Questionada por mim sobre a grade à sua porta, Dona Márcia, por fim, explicou que os moradores do Cantagalo são muito expansivos ("entrões") e que, dessa maneira, ela conseguia evitar "ter muito contato com essa vizinhança daqui [Cantagalo] na minha porta".

Tal fato chama atenção para a forma singular como esses moradores se apropriam do espaço comum do prédio projetado pelo PAC, subvertendo o uso dele esperado. Ao colocar essa grade no corredor antes de sua porta, Dona Márcia atualiza o significado do espaço em questão, ressaltando que as maneiras de utilizar o espaço dos moradores subvertem a lógica do planejamento da arquitetura, tal como nos ensina Certeau (1995). Nas mais diversas situações cotidianas, os moradores dessas duas favelas vizinhas enfatizam que "Cantagalo e Pavão-Pavãozinho não são a mesma favela", marcando, com isso, sua rivalidade e diferenciação identitária. É comum ouvir dos moradores do Cantagalo sobre os moradores do Pavão-Pavãozinho: “Eles ficam para lá e nós para cá. Eu não gosto de lá e não sei

1 Esse e os outros nomes citados ao longo do texto são fictícios, buscando preservar a identidade dos moradores e lideranças dessas favelas. 
nem andar lá direito!" A mesma narrativa pode ser frequentemente ouvida dos moradores do Pavão-Pavãozinho sobre a favela vizinha. O Estado e moradores apresentam, portanto, percepções conflitantes em relação à forma como concebem e tratam o espaço em questão. O Estado, nesse caso representado pelo PAC, percebe esse território como um todo integrado, coeso e uniforme: o "Complexo Pavão-Pavãozinho-Cantagalo". Já os moradores concebem a existência de duas favelas vizinhas, porém distintas: o Cantagalo e o Pavão-Pavãozinho.

A grade de Dona Márcia coloca em evidência essas categorias e práticas espaciais locais que não foram contempladas no projeto de (re)urbanização dessas favelas. Ainda que o PAC tenha buscado implementar seu projeto nessas favelas através de uma metodologia participativa, a situação descrita destaca que acabou atuando conforme o modelo tradicional "de cima para baixo": centralizado no Estado e respaldado em justificativas e argumentos técnicos dos interventores.

A situação acima foi por mim observada no ano de 2012 durante o trabalho de campo realizado para pesquisa de doutorado, na qual trabalhei com a implementação do PAC e da Unidade de Polícia Pacificadora (UPP) nessas duas favelas vizinhas. ${ }^{2}$ Tal trabalho de campo foi realizado de forma sistemática nos anos de 2011, 2012 e parte de 2013, incluindo, além da observação de inúmeras reuniões e atividades da vida associativa, também a observação de suas práticas sociais cotidianas e entrevistas abertas. Com isso, a pesquisa buscou descrever e analisar a forma como os moradores e lideranças percebiam e se colocavam diante do processo de intervenção urbana pelo qual passavam as duas favelas. ${ }^{3}$ Tal processo teve início em fins de 2007, envolvendo algumas das políticas públicas de maior visibilidade no âmbito político nacional, tal como o PAC, a UPP e ainda o processo de regularização urbanística e fundiária.

Ao apresentar uma breve contextualização sobre as políticas habitacionais no país, o presente artigo pretende, inicialmente, situar historicamente o projeto de (re)urbanização de favelas do PAC, destacando a mudança dos últimos anos em que a "participação popular" passou a ser condição para a liberação de recursos das obras físicas. Mais especificamente, através da etnografia, o texto

2 Ver Blasi Cunha (2014b).

3 Para uma discussão sobre as condições de realização desse trabalho de campo, ver Blasi Cunha (2014a). 
busca descrever e analisar a metodologia participativa proposta pelos agentes da "equipe social do PAC" e a forma como tal metodologia é posta em prática por esses agentes, ressaltando seus desafios e limitações. Por outro lado, o material etnográfico destaca a forma como moradores e lideranças buscam expor suas demandas nos "meios oficiais" que lhes foram disponibilizados pelo PAC, mas também alguns mecanismos alternativos acionados por eles na prática diante desse processo.

\section{Breve contextualização sobre políticas habitacionais no Brasil}

Desde o final do século XIX, a questão da habitação popular vem sendo percebida e tratada pelo poder público de formas variadas. Durante toda a Primeira República (1889-1930), período em que ocorreu o primeiro surto de crescimento urbano, surgiram alternativas de moradia destinadas a abrigar a crescente classe trabalhadora, como as várias modalidades de alojamentos coletivos e as vilas operárias, empreendidas por investidores para locação ou por empresas para abrigar seus empregados. Nesse período inicial, a ação do poder público na produção habitacional foi insignificante e, conforme destaca Bonduki (2014), a habitação social no Brasil surge apenas no período Vargas, quando o Estado abandona a postura de deixar a questão da construção, comercialização e locação habitacional ao mercado. Com a Revolução de 1930, o governo passou a intervir tanto no processo de produção como no mercado de locação habitacional. Embora a habitação tenha sido assumida como questão de responsabilidade pública, nesse momento, ainda não existia uma estratégia governamental estruturada para enfrentar o problema de forma abrangente.

A necessidade de mudança era evidente e ela emerge, numa configuração conservadora, no início dos anos 1960, culminando com o regime militar. A Aliança para o Progresso, executada pela agência United States Agency for International Developmen (Usaid - criada pelos Estados Unidos), apoiou projetos habitacionais de grande dimensão quantitativa e baixa qualidade de projeto, prenunciando a política a ser implementada no regime militar. Conforme destaca Valladares (2005), o programa mais significativo financiado pela Usaid foi a remoção de favelas localizadas na valorizada Zona Sul do Rio de Janeiro, desenvolvida pelo governador Carlos Lacerda (1961-1965), com a transferência 
de seus moradores para grandes conjuntos habitacionais na extrema periferia da cidade. Tal programa foi um prenúncio da política posteriormente implementada pelo Banco Nacional de Habitação (BNH).

Na percepção de Bonduki (2014), a despeito das críticas que possam ser feitas ao BNH e ao sistema financeiro por ele preconizado, é necessário reconhecer sua importância e caráter estratégico na estruturação de uma política habitacional para o país. Essa foi a primeira vez em que o país teve, de fato, uma política nacional de habitação e seus resultados quantitativos foram bastante expressivos. $\mathrm{O}$ autor destaca, no entanto, que tal política era baseada em princípios como centralização, sendo notável na concepção do projeto a localização dos conjuntos nas franjas urbanas, o desprezo pela qualidade do projeto e pela participação popular.

A crítica à arquitetura moderna, formulada na Europa e Estados Unidos a partir da década de 1950 (Jacobs, 2007; Turner, 1977), apenas encontrou espaço para se firmar no Brasil em meados dos anos 1970. No Brasil, tal crítica tendeu a focar a produção homogênea do $\mathrm{BNH}$, na qual era mais fácil encontrar exemplos de desastres urbanísticos e arquitetônicos. No processo de transição da ditadura para o regime democrático, surgiu um modelo de gestão em que a participação e o controle social interferiram positivamente na formulação de políticas públicas "inovadoras". Esse período se caracterizou, por um lado, pela extinção do BNH e ausência de uma política federal habitacional, e, por outro, pelo surgimento de programas "alternativos", promovidos, em geral, por administrações estaduais e municipais, que colocaram em prática propostas emanadas da sociedade, questionando o tecnicismo do modelo "de cima para baixo".

Inspirada na crítica marxista à divisão social do trabalho, a produção intelectual dos arquitetos passa a trabalhar os temas da autoconstrução em mutirão na chave das práticas de participação e democratização da habitação e da cidade. Esse ideário acabou por transformar-se em política oficial, ainda na década de 1980. Rizek, Barros e Bergamim (2003) chamam atenção ao fato de que, ao longo dessa transformação, as dimensões relativas à autogestão e às possibilidades de emancipação futura foram suprimidas. Ao mesmo tempo, nesse mesmo período, várias experiências tiveram lugar, retomando ou mesmo ampliando essa pauta na busca da diferenciação entre os programas oficiais e os discursos e práticas emancipatórias empreendidas pelos movimentos por habitação e suas ocupações. Os laboratórios de habitação e uma junção de práticas profissionais 
combinadas às práticas militantes de arquitetos e estudantes de arquitetura espalharam-se pelos territórios das periferias das grandes cidades.

Em 1983, governadores eleitos pela oposição, como Franco Montoro, em São Paulo, e Leonel Brizola, no Rio de Janeiro, iniciaram programas habitacionais "alternativos" ao modelo convencional do BNH. Brizola deu início a um programa de urbanização de favelas, inclusive da Zona Sul, enterrando as antigas práticas de remoção do governo militar. No Rio de Janeiro, além da urbanização de favelas, no período de 1983 a 1993, segundo Leitão et al. (2016), houve um significativo avanço dos movimentos de ocupação de terras urbanas e seu subsequente processo de regularização fundiária.

Em São Paulo, a antiga empresa habitacional do governo do estado foi redefinida e renomeada - passou a se chamar Companhia de Desenvolvimento Habitacional e Urbano (CDHU) - e foi criado um programa descentralizado, baseado em recursos orçamentários, bem como em parceria com municípios e organizações comunitárias, procurando produzir moradias a baixo custo, em sistema de mutirão gerido pelo próprio poder público. Das experiências municipais, o Programa de Habitação Social do Município de São Paulo, desenvolvido pela Superintendência de Habitação Popular (Habi) no governo de Luiza Erundina (1989-1922), foi considerado um laboratório de experiências participativas para enfrentar a questão de uma maneira inovadora.

Nas palavras de Bonduki (2014, p. 128), a partir da década de 1980, no período de transição para a democracia, o país passou

por um processo extremamente interessante de construção de uma política pública na área de desenvolvimento urbano e habitacional, uma verdadeira "bottom up public policy", ou seja, a construção de uma política pública "de baixo para cima" [...] A emenda de iniciativa popular da reforma urbana da Constituinte, que se desdobrou no Estatuto da Cidade, e o projeto de lei de iniciativa popular que propôs o Fundo Nacional de Habitação foram frutos da mobilização da sociedade, que teve um papel fundamental para a consolidação de uma política urbana e habitacional baseada na função social da propriedade e no direito à habitação.

Dessa maneira, conforme visto de forma resumida, o modelo "de cima para baixo" de utilização do saber técnico da arquitetura e urbanismo foi historicamente 
utilizado em políticas de produção de habitação popular e de urbanização de favelas no país. A partir da década de 1980, surgem algumas experiências "alternativas" de produção habitacional popular, que acabam se tornando políticas públicas. A ideia de que a participação popular é importante e necessária na elaboração e implementação de políticas públicas vai ganhando força até o momento em que se torna um pré-requisito para a aprovação e liberação do orçamento de obras públicas do governo federal.

Esse é o caso do "PAC-Favelas", divulgado como sendo diferente das políticas habitacionais anteriores por sua forte marca de "gestão participativa". O "trabalho social" é nele uma condição necessária e determinante para a realização de obras físicas. O documento que orienta ação do trabalho social do PAC chama-se COTS - Caderno de orientação técnica social - programas setor público e é elaborado pela Caixa Econômica Federal, que é o agente operador e tem como atribuição analisar o Projeto de Trabalho Técnico Social, acompanhar, atestar e avaliar sua execução. Em tal documento fica claro o objetivo geral que norteia o trabalho social das obras do PAC:

O Trabalho Técnico Social é o conjunto de ações educativas planejadas pelo proponente [...] adequadas à realidade socioeconômica e cultural da população e às características da área de intervenção, respeitando as diretrizes dos Programas, com o intuito de promover a mobilização e organização comunitária, a educação sanitária e ambiental, a capacitação profissional e/ou geração de trabalho e renda, procurando atender às principais demandas sociais existentes. Seu objetivo é a criação de mecanismos capazes de viabilizar a participação dos beneficiários nos processos de decisão, implantação e manutenção dos bens/ serviços, a fim de adequá-los às necessidades e à realidade dos grupos sociais atendidos, bem como incentivar a gestão participativa, garantindo a sustentabilidade do empreendimento (COTS, 2004, p. 5).

Criar mecanismos para tornar viável a participação dos "beneficiários" nas decisões e implantação do projeto passa a ser uma medida buscada nos programas habitacionais. As obras físicas passam a ter o acompanhamento obrigatório do "trabalho social", no intuito de cumprir com a recomendação de promover a "participação comunitária". Dessa forma, a categoria "gestão participativa" tornou-se uma referência central nas políticas públicas dos últimos anos no país. 
A breve contextualização histórica sobre políticas habitacionais, além de situar a atual política do PAC e sua metodologia participativa, permite ainda destacar que o Estado não esteve ausente das favelas ao longo do século XX e neste início de XXI. Não se trata de ausência do Estado, mas sim de uma forma específica de atuação nesses territórios, através da qual ele produziu e consolidou ali as suas margens. Conforme mostrado acima, não é de hoje que o poder público atua nas favelas da cidade, e a forma específica através da qual sempre se relacionou com elas foi, inclusive, uma das principais propiciadoras do surgimento e consolidação destas no tecido urbano da cidade. As favelas serão aqui pensadas como margens, no sentido proposto por Das e Poole (2008) ou Vieira da Cunha e Feltran (2014), que se negam a pensá-las na chave da ausência ou da exclusão, e, muito pelo contrário, buscam abordá-las em suas relações com o centro, destacando seus papéis necessários ao funcionamento da cidade.

Ressaltar essa relação histórica entre poder público e favelas, não significa, no entanto, negar o diferencial da absoluta centralidade que, recentemente, as favelas assumiram nas políticas urbanas da cidade do Rio de Janeiro. Tal centralidade é interpretada pela bibliografia sobre o tema a partir do contexto de preparação da cidade para a Copa do Mundo de 2014 e os Jogos Olímpicos de 2016, na qual a "retórica da integração" é frequentemente acionada. De acordo, por exemplo, com Cavalcanti (2013, p. 196):

O PAC-Favelas foi concebido em consonância com as exigências do planejamento estratégico e de marketing urbano que vêm dando o tom da construção política, discursiva e imaginária de uma cidade apta a sediar megaeventos globais como a Copa de 2014 e as Olimpíadas de 2016, entre outros.

\section{Sobre o PAC}

O Programa de Aceleração do Crescimento (PAC) é um programa do governo federal, lançado em 2007, pelo governo do ex-presidente Luiz Inácio Lula da Silva, que se estendeu, no período de 2010 a 2014, no governo de Dilma Rousseff. No documento oficial de lançamento do PAC foram anunciados os investimentos em infraestrutura que, aliados a medidas econômicas, visavam a estimular os setores produtivos e levar benefícios sociais para todas as regiões do país. Em tal 
documento estava colocado como objetivo "acelerar o crescimento econômico do Brasil para gerar mais emprego e renda e reduzir as desigualdades regionais". ${ }^{4}$ Apresentada como uma das mais amplas políticas de desenvolvimento das últimas décadas, o programa do PAC previa, em sua primeira etapa, investimentos da ordem de R\$ 500 bilhões para o período de quatro anos (2007 a 2010), dos quais $\mathrm{R} \$ 106$ bilhões seriam destinados para a área de habitação. Os eixos fundamentais do programa, elencados em tal documento, eram: Investimento em Infraestrutura; Estímulo ao Crédito e ao Financiamento; Melhoria do Ambiente de Investimento; Desoneração e Administração Tributária; Medidas Fiscais de Longo Prazo; Consistência Fiscal. A área de investimento em infraestrutura está subdividida em três linhas específicas: Logística (Rodovias, Ferrovias, Portos, Aeroportos e Hidrovias); Energia (Geração e Transmissão de Energia Elétrica. Petróleo, Gás Natural e Combustíveis Renováveis); Social e Urbano (Saneamento, Habitação, Transporte Urbano, Luz para Todos e Recursos Hídricos).

Apesar de ser concebida e implementada como uma política pública de desenvolvimento econômico e social no âmbito nacional, o PAC se orienta localmente de acordo com as especificidades das diferentes demandas das regiões nas quais atua, e caracteriza-se, portanto, como uma política pública semifocada. Na cidade do Rio de Janeiro, o setor de "infraestrutura social e urbana" do PAC atuou através de ações concebidas e implementadas especificamente para uma determinada região da cidade, as favelas, e não para a cidade como um todo. A especificidade da atuação dessa política que se volta para a (re)urbanização das favelas da cidade reflete-se na alcunha "PAC-Favelas". A atuação se deu, inicialmente, nas favelas de grande porte, isto é, os aglomerados de favelas, os chamados "complexos", tendo depois se estendido a outras favelas menores. As três maiores obras do PAC-Favelas foram realizadas em três complexos: Alemão, Manguinhos e Rocinha.

No momento do lançamento do projeto, o valor do investimento em favelas no estado do Rio de Janeiro era de R\$ 1,3 bilhão, do qual R\$ 495 milhões para o Complexo do Alemão, R\$ 235 milhões para Manguinhos, R\$ 110 milhões para Rocinha e R\$ 35,2 milhões para o "Complexo Pavão-Pavãozinho-Cantagalo". A articulação entre as diferentes esferas administrativas (municipal, estadual

4 Em http://www.dnit.gov.br/menu/pac/pac_inicio (acessado em 15/04/2008). 
e federal) no planejamento, execução e, sobretudo, financiamento dessa política é apontada como um dos diferenciais do PAC em relação às intervenções anteriores.

O PAC foi lançado no "Complexo Pavão-Pavãozinho-Cantagalo" em novembro de 2007, com a presença do então presidente da República, Luiz Inácio Lula da Silva, do ministro das Cidades, Márcio Fortes de Almeida, e do governador Sérgio Cabral. Em seu discurso aos moradores e à imprensa Lula prometeu: "Vamos transformar essa e outras comunidades, como a Rocinha, Manguinhos e o Alemão, em lugares dignos para se morar, que permitam a vocês a conquista da cidadania". ${ }^{5}$ Apesar de o PAC ter sido oficialmente lançado no "Complexo Pavão-Pavãozinho-Cantagalo" em novembro de 2007, sua proposta foi apresentada aos "moradores" apenas em março de 2008, na "Primeira Grande Reunião de Moradores". O projeto apresentado compunha-se basicamente por dois eixos centrais de ação: (1) obras físicas que integram o "programa de reurbanização" da favela; e (2) as "ações sociais" que fazem parte do "trabalho social" do PAC.

Para que as propostas do PAC de "tratamento paisagístico", "ampliação de praças", "construção de playgrounds" e, sobretudo, "alargamento de ruas" se tornassem realidade, aproximadamente 250 famílias seriam desalojadas de suas casas até o término das obras, inicialmente previsto para o final de 2009. A "participação comunitária" viabilizada pelo programa restringia-se, no entanto, às propostas de ação do "trabalho social", não contemplando nenhum tipo de consulta aos moradores em relação à intervenção das obras físicas que ali seriam realizadas. Segundo o trecho do jornal editado e distribuído na favela pelo PAC:

Este programa de aceleração do crescimento - PAC - veio com um formato novo onde há uma especial atenção com a qualidade dos processos participativos. Foram editadas novas instruções normativas do Ministério das Cidades e da Caixa Econômica para o PAC em todo o Brasil sobre o assunto, que representam um grande avanço para a governança social sobre a execução de intervenções e obras públicas. Considera-se beneficiário do projeto quem reside na comunidade. Como o projeto é uma herança de uma obra contratada antes do PAC, em 2006, é mais difícil alterar o projeto físico. O projeto social, no entanto, comporta

5 Em http://www.transportes.proderj.rj.gov.br/noticia_29.html (acessado em 21/08/2008). 
alterações, o que está acontecendo continuamente, e para melhor, com a contribuição participativa do Conselho Comunitário do Projeto-CCOMP.

Quando indagado a respeito das inúmeras demolições previstas para todos os "complexos" onde o PAC atuaria, o subsecretário de Urbanismo da Secretaria de Obras, Vicente Loureiro, em 5 de março de 2008, declarou ao Globo: "Não se faz um omelete sem quebrar ovos. É preciso abrir avenidas, preservar a faixa marginal de canais e combater a área de risco. Isto provocará a demolição de casas" (Estado..., 2008). Desde então, foram construídos pelo PAC no Cantagalo dois prédios para realocar moradores, tanto do Pavão-Pavãozinho como do Cantagalo, que tiveram que deixar suas casas devido às obras físicas, sobretudo pelo alargamento de ruas. Cada um dos dois prédios já construídos no Cantagalo possui dois blocos de apartamentos, totalizando quatro blocos e 150 apartamentos. Os apartamentos são de dois quartos, sala, cozinha e banheiro, distribuídos em uma área de $42 \mathrm{~m}^{2}$.

Em junho de 2010 foi inaugurado também no Cantagalo um monumental elevador panorâmico ligando o bairro de Ipanema à favela e também um mirante, formando o chamado "Complexo Rubem Braga". ${ }^{6} \mathrm{O}$ "complexo" foi construído pelo Metrô-Rio em parceria com o PAC, sendo formado por duas torres com elevadores panorâmicos, um mirante, acesso à então recém-inaugurada estação de metrô General Osório e uma passarela que liga essas torres a uma região do Cantagalo conhecida como Quebra-Braço.7

Além dos elevadores atualmente serem um dos acessos dos moradores do Cantagalo à favela, o chamado "Mirante da Paz" tornou-se o mais novo ponto turístico de Ipanema com vista para a praia de Ipanema e do Leblon e para a Lagoa Rodrigo de Freitas. No vídeo de apresentação do elevador, elaborado pelo Governo do Estado do Rio de Janeiro (gestão de Sérgio Cabral), diz-se que o elevador "é o verdadeiro elo de uma cidade que não está mais partida". Logo na sequência é exibida uma entrevista com Zuenir Ventura, autor do livro Cidade partida (Ventura, 1994), na qual o autor ressalta que esse é um gesto simbólico na direção de se "criar pontes e não muros" entre partes da cidade.

6 Rubem Braga foi um renomado cronista brasileiro que, após ter vivido em diversas cidades brasileiras, escolheu Ipanema como lugar de residência até o fim de sua vida.

7 A empresa responsável pela sua construção foi a Odebrecht Infraestrutura. 
O elevador tem proporções monumentais e, sobretudo à noite, quando suas luzes de neon verde são acesas, inscreve fortemente sua presença no bairro de Ipanema. Cavalcanti (2013) destaca que a forma como o PAC opera a inscrição das favelas na paisagem da cidade é o seu principal diferencial em relação às políticas habitacionais anteriores já implementadas no Rio de Janeiro. A autora analisa alguns desses símbolos do propalado discurso de integração entre favela e asfalto inscritos pelo PAC na paisagem urbana. Além do elevador do Cantagalo, a autora descreve a passarela projetada na Rocinha por Oscar Niemeyer (PAC-Rocinha), o famoso teleférico do Alemão (PAC-Alemão) e a praça que concentra todos os novos equipamentos urbanos em Manguinhos (PAC-Manguinhos). A autora ressalta que aquilo que salta aos olhos nos casos em questão não é a favela em si mesma, mas o modelo e discurso da suposta integração entre favela e asfalto. Em suas palavras, os projetos do PAC "produzem um regime ambíguo de (in)visibilidade desse espaço, na medida em que não é a favela, como tal, que sobressai na paisagem, mas o espetáculo de sua 'integração' à cidade" (Cavalcanti, 2013, p. 206).

Ao longo da atuação do PAC no "Complexo Pavão-Pavãozinho-Cantagalo", além dos prédios, elevador e "alargamento de vias", houve também investimentos em recapeamento de ruas e na rede de esgotamento sanitário e água. Muitas das metas propostas, no entanto, não foram concluídas ao fim de 2009 , tal como previsto no projeto inicial. As obras foram retomadas em fins de 2011, já no governo Dilma Rousseff, quando o chamado "PAC 2", além de dar início ao processo de remanejamento de famílias para o alargamento de ruas no Cantagalo (Rua Custódio Mesquita) e no Pavão-Pavãozinho (Avenida Pavãozinho), anunciou também o início da construção de mais algumas unidades habitacionais, da reforma do chamado "casarão" e a construção de uma quadra poliesportiva no Pavão-Pavãozinho.

\section{A metodologia participativa do PAC}

O material etnográfico fruto das reuniões realizadas pela "equipe de trabalho social" do PAC 2 traz importantes contribuições para pensar na proposta de "gestão participativa" do PAC no "complexo" e, de uma perspectiva mais geral, sobre a participação popular em políticas públicas do país. Após as reuniões 
de 2008 e 2009 referentes ao PAC 1, estas voltaram a acontecer a partir de novembro de 2011, quando as obras do PAC foram retomadas, sob a alcunha de PAC 2. Tais reuniões pretendem ser uma espécie de "canal de comunicação" entre moradores, lideranças locais e os interventores do PAC com o objetivo de estabelecer o chamado "processo participativo das intervenções do PAC 2 nessa comunidade". As reuniões são convocadas e organizadas pela "equipe de trabalho social" do PAC e são comuns aos moradores do "Complexo Pavão-Pavãozinho-Cantagalo". Ao longo de todo o ano de 2012, acompanhei essas reuniões e pude observar os "canais oficiais" que são disponibilizados pelo PAC aos moradores e lideranças para que possam expor suas demandas e "participar" da implementação dessa política pública. A "equipe de trabalho social" é composta por uma assistente social, um arquiteto e alguns "agentes comunitários". Essa equipe promove reuniões com moradores e lideranças para a discussão de questões e dúvidas sobre o projeto e busca ainda fazer a mediação entre estes e os engenheiros e arquitetos da construtora responsável durante a apresentação das obras.

Nas primeiras reuniões do PAC 2 estavam presentes apenas algumas lideranças locais, "autoridades" e a "equipe de trabalho social". O objetivo anunciado era a apresentação dessas pessoas, do projeto das obras e do "trabalho social" a ser desenvolvido pela equipe ao longo do processo. Para o PAC 2 foi aberto um outro processo de licitação, tendo vencido uma nova construtora. Além disso, a supervisão do trabalho social também não mais seria responsabilidade da construtora contratada. No PAC 2, o trabalho social passou a ser supervisionado pelo Escritório de Gerenciamento de Projetos do Governo do Rio de Janeiro - Casa Civil do Estado (EGP-Rio). Dessa maneira, os relatórios da "equipe de trabalho social" precisam ser aprovados pelo EGP-Rio antes de ir para Caixa Econômica e ter seu orçamento liberado. O orçamento do PAC 2 era de R\$ 43 milhões para 12 meses de obra física e de R\$ 1 milhão para os 18 meses de "trabalho social".

Na primeira dessas reuniões, após a apresentação das obras pelos técnicos, logo foi dado, pelo então vice-governador do Estado do Rio de Janeiro, o "tom participativo" que se buscava estabelecer na realização dessas obras. Segundo Luís Fernando de Souza, conhecido como Pezão: “Não há demandas inventadas e tudo que está no projeto foi discutido com a comunidade. A equipe de trabalho social está aqui para ouvir e conversar com vocês e nenhuma ação 
será tomada sem o diálogo com as lideranças daqui." Nessas reuniões iniciais, a assistente social da equipe enfatizou em sua fala a importância de "pactuarem" com os moradores uma "visão de futuro comunitário" ou de estabelecerem um "pacto cívico comunitário". Para que esse "pacto" entre eles fosse estabelecido, a assistente social apresentou às lideranças locais os cinco canais de participação disponíveis a elas no projeto: o canteiro social, o CCOMP, as comissões temáticas, o $1^{\circ}$ Fórum Popular e as oficinas do imaginário.

O "canteiro social" é a base ou o escritório da equipe de trabalho social nas favelas e local onde os moradores podem ir tirar suas dúvidas e expor demandas relacionadas ao projeto. Apesar de terem buscado um espaço no Pavão-Pavãozinho para alocar a base do "canteiro social", ela acabou sendo estabelecida no Cantagalo, num dos apartamentos construídos no PAC 1 e ainda vazio. O CCOMP é o Conselho Comunitário do Projeto do qual as lideranças participam através de reuniões, assim como das comissões temáticas de seus interesses, sendo elas: 1) Comissão de Acompanhamento de Obras (CAO); 2) Comissão de Educação Sanitária, Ambiental e Patrimonial e 3) Comissão de Trabalho e Renda. Cada uma dessas comissões teria que realizar 12 reuniões com a participação de seus integrantes para "junto à equipe, pensar em um jeito melhor de fazer as coisas acontecerem". O “Fórum Popular" seria realizado em breve e nele o projeto seria apresentado aos moradores e esses poderiam expor publicamente duas demandas. Já a "oficina do imaginário", segundo descreveu a assistente social, seria uma metodologia na qual, através de desenhos, os moradores e lideranças poderiam expressar o "ideal de comunidade que sonham para o futuro".

Ao mesmo tempo em que nessas primeiras reuniões o objetivo do trabalho social e seu "tom participativo" são expostos pela equipe e autoridades, nelas logo também se evidenciam as insatisfações dos líderes locais presentes, em relação à experiência anterior do PAC 1 e a outras intervenções do Estado, que ali já foram implementadas. Logo nas primeiras reuniões, um dos líderes do Pavão-Pavãozinho, Pedro, perguntou se dessa vez teriam acesso ao "cronograma físico-financeiro da obra", para que pudessem saber quanto estava sendo gasto em cada etapa e avaliar se o dinheiro estava sendo bem empregado. Nessa e em várias outras reuniões Pedro insistiu nesse assunto e ressaltou que a transparência nos gastos era a única maneira de poder ser dito que as lideranças estavam de fato participando do acompanhamento das obras. 
Ironicamente, o líder disse que, sem acesso ao cronograma físico-financeiro, a Comissão de Acompanhamento das Obras seria um caô ${ }^{8}$ e não CAO, como a Comissão é chamada pelos agentes do PAC. Uma liderança antiga do Pavão-Pavãozinho, Constantino, coloca uma importante questão relativa à participação que é oferecida a lideranças e moradores pelo PAC; em suas palavras: "O projeto já veio pronto para nós e agora a gente integrar essas comissões e participar disso é complicado porque a comunidade vai cair de pau no projeto, mas ele já está pronto! O projeto já chegou até nós pronto e não podemos mudar muita coisa!" Ainda que com muito ceticismo e questionamento, as lideranças do Cantagalo e do Pavão-Pavãozinho se inscreveram para integrar o CCOMP através das comissões temáticas, de acordo com seus interesses e disponibilidade.

O formato proposto inicialmente para o $1^{\circ}$ Fórum Popular foi motivo de forte conflito em uma das reuniões que o precederam. Ainda que os embates entre lideranças e os agentes do PAC sejam presentes em praticamente todas as reuniões, esse, em específico, mostra-se importante por revelar a forma como a "participação" das lideranças é pensada pelos agentes do PAC e ainda o modo como elas atuam diante disso. Segundo os agentes da equipe de trabalho social, o fórum teria início com a fala dos presidentes das duas associações de moradores e, logo depois, viria a apresentação do projeto do PAC pelos técnicos e agentes interventores. Primeiro estes falariam sobre o que já foi realizado no PAC 1 e, na sequência, sobre o projeto do PAC 2. Além dos representantes da equipe de trabalho social, arquitetos, engenheiros e diretores da construtora responsáveis fariam suas devidas apresentações. Após a apresentação do projeto, haveria um "coffee break" e, apenas em seguida a essa pausa, o fórum seria retomado para que os moradores pudessem colocar suas questões.

O formato do fórum foi apresentado às lideranças apenas na intenção de que tomassem consciência de como este havia sido planejado pela equipe. O tom da apresentação da equipe era mais informativo do que o de um planejamento coletivo em relação ao formato desse $1^{\circ}$ Fórum Popular. Pedro, líder do Pavão-Pavãozinho, no entanto, perguntou, em tom de crítica, o porquê da realização desse "coffee break" antes do tempo destinado às questões dos moradores. Logo, outros líderes começaram também a intervir e a dizer que isso era

8 "Caô" é uma gíria carioca que designa mentira, lorota ou história contada a alguém com o intuito de enganar. 
estratégia deles para esvaziar a reunião. Os agentes do PAC tentaram argumentar que o "coffee break" após a apresentação do projeto havia sido planejado apenas para que a reunião se tornasse menos cansativa. Após uma discussão bem tumultuada ficou "pactuado" entre líderes e a equipe que o "coffee break" se daria somente após a fala dos moradores.

Em meio a essa discussão, outra questão surgiu, gerando ainda mais confusão e aumentando o clima combativo da reunião: a forma como se daria a participação dos moradores no $1^{\circ}$ Fórum Popular. Os líderes discordaram do fato de que os moradores não teriam direito a fazer uso da palavra. De acordo com a proposta da equipe, nem lideranças e nem moradores teriam espaço para fazer suas perguntas diretamente no microfone. Os agentes da equipe do PAC anunciaram às lideranças que aqueles que tivessem dúvidas sobre o projeto deveriam escrevê-las em um papel que seria distribuído no início do fórum. Tais perguntas passariam por uma seleção feita pela própria equipe para que então fossem lidas no microfone pela cerimonialista a fim de que os técnicos responsáveis as respondessem.

Os agentes do PAC social argumentaram que aquele modelo havia sido pensado apenas para evitar repetições de questões e não ultrapassar o tempo previsto para a realização do fórum. Os líderes logo se manifestaram dizendo que, no mínimo, pelo menos um deles deveria participar, junto à equipe, desse processo de seleção das perguntas dos moradores a serem lidas. Após mais discussão para saber quem seria esse líder, ficou decidido que Pedro, liderança do Pavão-Pavãozinho, desempenharia essa função no dia do $1^{\circ}$ Fórum Popular. O tempo e formato de participação das lideranças previsto pela equipe de trabalho social era bastante limitado. Isso não significou, no entanto, o silenciamento desses líderes, durante o fórum. Alguns deles, ainda que sem microfone, elevaram o tom de sua voz, tomaram a palavra e se pronunciaram, expondo dúvidas e críticas sobre a implementação do projeto e, sobretudo em relação à falta de informações sobre a demolição de casas para o alargamento de ruas.

O mesmo tom informativo da reunião de planejamento do $1^{\circ}$ Fórum Popular perpassou aquela em que o projeto de alargamento da Avenida Pavãozinho foi finalmente apresentado em detalhes aos moradores. A Associação de Moradores do Pavão-Pavãozinho estava repleta de moradores, como raramente se vê nas habituais reuniões. $\mathrm{O}$ arquiteto da equipe de trabalho social apresentou aos moradores, com a ajuda do PowerPoint, o mapa com o trecho da Avenida Pavãozinho que teria as casas demolidas para possibilitar o alargamento dessa via. 
A engenheira da construtora responsável pela execução do projeto estava presente na reunião e foi auxiliando o arquiteto da equipe de trabalho social em sua apresentação. $O$ arquiteto parecia buscar fazer uma espécie de tradução do mapa e das orientações técnicas da engenheira para os moradores e lideranças presentes.

Ninguém melhor, no entanto, que os próprios moradores para identificarem no mapa as suas casas e as dos seus colegas ali presentes. Os moradores mais jovens fizeram-no e anunciaram àqueles com a vista mais cansada as casas que sairiam. Em tom de deboche e revolta, o líder Pedro, que também teria sua casa demolida, foi falando para os moradores que não conseguiam localizar suas casas no mapa: "Ali naquele pedaço perto do bondinho pega a casa de vocês quatro aí. Só naquele trechinho ali lambeu a casa de vocês quatro!"

Muitas foram as perguntas dos moradores e pouco satisfatórias eram as explicações da equipe de trabalho social e dos engenheiros responsáveis, por não possuírem um bom conhecimento das marcações espaciais que orientam a percepção dos moradores da área em questão. Os agentes da equipe social tentaram acalmar os moradores e voltar a tratar da questão que envolve o processo de negociação das casas. Tais agentes começaram, então, a explicar as três opções disponíveis no processo de negociação das casas. Além dos prédios que serão construídos, o PAC oferece ainda duas outras opções: a indenização e a compra assistida.

O valor da indenização oferecida era estipulado por um decreto do governo estadual e é geral para a avaliação de casas a serem remanejadas em diferentes regiões do estado. A indenização era calculada de acordo com as benfeitorias e qualidade de cada construção, não sendo levada em consideração a localização dessas casas, e nivelavam, portanto, o preço desses imóveis por baixo. Os imóveis dali já eram caros pela localização das favelas em bairros nobres da cidade. Com a "pacificação" e obras sendo realizadas, os imóveis se tornaram ainda mais caros e, dessa maneira, com os baixos valores de indenização pagos pelo PAC, não era possível comprar imóveis no "Complexo Pavão-Pavãozinho-Cantagalo". Além disso, a opção de compra assistida também não era viável porque quase não havia imóveis disponíveis à venda nessas favelas e os que existiam estavam com preços bem além do que o PAC estava disposto a pagar.

Dessa maneira, das três opções oferecidas pelo PAC aos moradores, apenas uma era realmente viável àqueles que desejavam permanecer morando 
no chamado "Complexo Pavão-Pavãozinho-Cantagalo": os apartamentos. Os moradores entenderam rapidamente a situação e, após a apresentação das três opções, um diálogo entre uma moradora e a engenheira responsável pela execução da obra trouxe à tona a situação dramática que envolve todo o processo de remanejamento desses moradores: a engenheira não sabia o total de apartamentos que realmente seria construído. Mais uma vez, Pedro, líder do Pavão-Pavãozinho, chamou atenção dos moradores para essa situação:

Quando vocês forem negociar a casa de vocês, lembrem-se disso! Não sabemos se tem apartamentos para todos nem quando estarão prontos. Se tiver 100 apartamentos e 150 famílias para sair, a gente não sai! Estamos falando das nossas casas e cada um aqui é que sabe o quanto ralou para construir! São nossas casas! Não são figurinhas que tira daqui e bota lá!

Os agentes da equipe buscaram explicar aos moradores que aqueles que fizessem a opção pelos apartamentos do PAC deveriam começar a buscar uma casa para alugar até que os apartamentos ficassem prontos. Explicaram ainda que, enquanto os prédios não ficassem prontos e os moradores permanecessem nessas casas alugadas, eles receberiam do governo o chamado "aluguel social", no valor de $\mathrm{R} \$$ 450,00, para pagarem pela moradia provisória.

Alguns moradores e líderes começaram a reclamar em voz alta do preço do aluguel social e das indenizações pagas pelo PAC alegando que elas não condizem com a realidade dos preços do "Complexo Pavão-Pavãozinho-Cantagalo". Uma agente da equipe procurava explicar o decreto e como é feito o cálculo da indenização, mas os moradores a interromperam. Em tom de indignação, os moradores e lideranças questionaram tudo o que a equipe tentava explicar, alegando que ali é tudo caro e não havia imóveis disponíveis naqueles valores oferecidos, nem para alugar e nem para comprar. Um morador se levantou e disse a seguinte frase: "Aluguel de 400 reais aqui?! Se você encontrar, me avisa logo, tá?! Esse negócio de fazer a rua e só depois os prédios está por fora! Os prédios têm que ser primeiro!" Dito isso, tal morador foi embora da associação, dando início ao que acabou sendo o tumultuado encerramento dessa reunião.

Nas seguintes reuniões do CCOMP, todos esses assuntos críticos relacionados ao chamado "remanejamento" voltaram a aparecer em perguntas de moradores. Algumas reuniões e muitas reclamações depois, no dia 2 de maio de 2012 
aconteceu uma reunião para tratar especificamente do valor da indenização e do aluguel social. Os moradores haviam cobrado em reuniões anteriores que essa demanda fosse encaminhada para os responsáveis e essa situação revista. Constantino, líder do Pavão-Pavãozinho, havia sugerido que fosse redigido e encaminhado um ofício para o governo do estado.

Após alguma discussão, ficou resolvido que o ofício seria encaminhado em nome do CCOMP. Feito isso, agentes da equipe de trabalho social e lideranças foram redigindo coletivamente o ofício que buscava uma diferenciação nos valores das indenizações e aluguel social pagos aos moradores dali. No ofício tentaram deixar claro que o valor de mercado dos imóveis do "Complexo Pavão-Pavãozinho-Cantagalo" era elevado e não poderia ser equiparado com o de favelas distantes da valorizada Zona Sul onde o PAC também atua como, por exemplo, Manguinhos. Na reunião seguinte, os agentes do PAC disseram que o ofício havia sido encaminhado e que ficaram sabendo que os responsáveis estavam buscando soluções para aumentar o valor do aluguel social, mas que o da indenização seria bem difícil.

Em todas essas reuniões, fotografias foram feitas, assinaturas recolhidas e atas elaboradas pelos agentes da equipe de trabalho social. Todo esse material serviu de base para os relatórios que a equipe precisa encaminhar a fim de serem avaliados e, caso aprovados, a verba liberada. A sociologia pragmatista francesa, e em especial o trabalho de Boltanski e Thévenot (1991), oferece uma interessante ferramenta analítica que permite abordar esses processos a partir da percepção dos próprios atores de situação em situação. Os autores destacam que a confrontação com uma situação problemática coloca em evidência os procedimentos de transação através dos quais os atores apaziguam suas diferenças e, mesmo de forma conflitual, produzem modos de "se engajar" numa situação selecionando finalidades e objetivos. Tais autores colocam o foco da análise em situações nas quais acordos são estabelecidos buscando o "bem comum" e o "viver junto".

Nas reuniões seguintes, os moradores continuaram sendo incentivados a receberem a equipe para fazerem o cadastro e depois negociarem suas casas. Diante dessa situação desfavorável e de indefinição, muitos moradores negavam-se a receber os agentes do PAC social para a realização do cadastro. Assim, não era possível saber quantos moradores sairiam de suas casas ao certo e, em momento algum, o número de quantos deles ficaria sem apartamentos 
foi apresentado aos moradores. A situação tornou-se uma espécie de "bola de neve", na qual os moradores não aceitavam se cadastrar por conta da indefinição em relação ao número de apartamentos e dos baixos valores de aluguel social e indenização. Sem o cadastro, não era possível saber quantas eram as famílias que sairiam e quantas ficariam sem apartamentos. A situação seguia indefinida.

No mês de agosto de 2012, os moradores receberam a informação da equipe de trabalho social de que haviam conseguido o reajuste do aluguel social de $\mathrm{R} \$ 450,00$ para $\mathrm{R} \$ 650,00$, mas que, em relação aos valores da indenização, nada pôde ser feito. Na reunião de 22 de novembro de 2012, foi anunciado que o cronograma da obra estava sendo revisto e as obras passariam de 12 para 24 meses, enquanto o "trabalho social" de 18 para 30 meses. Dessa reunião participou um engenheiro da construtora responsável pela fiscalização do projeto que até não era conhecido pelos moradores. Esse engenheiro esclareceu que o PAC 2 estava intervindo na comunidade há um ano e que esse era o prazo inicial para a conclusão das obras. Nesse um ano, no entanto, segundo o engenheiro, apenas $5 \%$ do projeto havia sido executado. Dessa maneira, a Caixa Econômica Federal havia cobrado resultados e, diante disso, ficou decidido que a supervisão do trabalho social fosse substituída, passando das mãos do EGP-Rio para as da Secretaria de Estado de Obras (Seobras). ${ }^{9}$

Ao longo da reunião, o engenheiro falou em um tom bastante alterado sobre o problema do atraso das obras e atribuiu claramente a responsabilidade desse atraso ao fato de muitos moradores estarem se negando a sair de suas casas e a negociar, "entravando", assim, a execução do alargamento da Avenida Pavãozinho. Diferente do tom de fala habitual dos outros técnicos da construtora e, sobretudo, dos agentes da equipe do trabalho social, tal engenheiro, ao longo da reunião, disse que "as pessoas não querem sair e estão sacaneando a obra, mas nós vamos construir essas ruas! Os moradores vão ter que sair. Nós estamos aqui para resolver isso!" Dito isso, tal engenheiro encerrou sua fala dizendo que até então eles estavam sendo "bastante tolerantes".

9 De acordo com o site da Seobras: "A Secretaria de Obras tem por finalidade planejar, organizar, orientar, coordenar, supervisionar e avaliar as ações setoriais a cargo do Estado relativas ao desenvolvimento viário, urbano, edificações e saneamento básico, mecanismos de regulação para a concessão de serviços ou estabelecimento de parcerias público-privadas" (ver: http:// www.rj.gov.br/web/seobras/exibeconteudo?article-id=140626, acessado em 30/01/2017). 


\section{Considerações finais}

Em seu material de divulgação, O PAC foi frequentemente anunciado como um exemplo de política habitacional que, diferentemente das anteriores que por ali passaram, procurava superar a centralização, o autoritarismo e o tecnicismo. O material etnográfico chama atenção, no entanto, para um projeto de intervenção urbana que, ainda que tenha buscado formular e trabalhar com metodologias participativas, acabou não contemplando as percepções e práticas dos moradores na elaboração e implementação do seu projeto. Conforme descrito no início deste artigo, a grade instalada por Dona Márcia na porta do seu apartamento chama atenção para a maneira como os moradores, através de suas práticas cotidianas e formas de apropriação do espaço, buscam contornar ou driblar a imposição de um ordenamento espacial que colocou, no mesmo corredor de um prédio, famílias oriundas de favelas vizinhas, que possuem uma relação marcada historicamente pela hostilidade.

Diversos autores chamaram atenção para o fato dos idealizadores dos projetos não incorporarem no planejamento urbano as dimensões sociais do processo e as categorias e práticas espaciais. Já em 1961, Jacobs (2007) promove uma crítica contundente ao racionalismo dos planejadores urbanos, que, amarrados aos seus arcabouços teóricos, não levam em consideração em seus planos de intervenção a complexidade da realidade urbana. Nessa mesma direção, preocupados com a não incorporação dos usos sociais do espaço e com a democratização do planejamento urbano, destacamos, dentre sociólogos, antropólogos e arquitetos, os trabalhos de Vogel, Mello e Mollica (2017), Leite (2004), Bonduki (1992) e Holston (1993).

Apesar da forte retórica de "gestão participativa", dos conselhos criados e das inúmeras reuniões realizadas pela "equipe de trabalho social" do PAC, o fato é que esse projeto chegou até os moradores pronto para ser executado e já aprovado em esferas heterônomas. Ao mesmo tempo em que as lideranças locais são convidadas a "participar" do processo de intervenção, são também considerados "multiplicadores" do projeto pela "equipe de trabalho social" do PAC. A ideia de que apenas reproduziriam e legitimariam o projeto perpassa de forma bastante clara o título de "multiplicadores" atribuído às lideranças locais. Na prática, portanto, ao longo da implementação desse programa, uma série de demandas, saberes e categorias locais, importantes nas formas 
de classificação e apropriação do espaço, não foram incorporadas ao projeto por parte dos técnicos idealizadores das obras. O projeto foi elaborado centrando-se em fundamentos técnicos sobre alargamento de ruas, acessibilidade e adensamento, com nenhuma perspectiva de democratização do saber técnico da arquitetura.

A retórica da "participação" foi frequentemente acionada pelos agentes interventores do PAC e por autoridades responsáveis, ainda que, na prática, não houvesse possibilidade da construção de um projeto conjunto de obra física, que contemplasse demandas dos moradores. Essas reuniões do CCOMP, por vezes, aparentavam um caráter muito mais informativo do que consultivo e participativo de fato. Dentro da grandiosidade de todo esse projeto, o que foi passível de negociação com os moradores e lideranças eram detalhes como, por exemplo, a, frequentemente por eles citada, inclusão de um corrimão em uma das escadarias de acesso ao topo do Pavão-Pavãozinho. Como bem percebeu e advertiu Constantino, líder do Pavão-Pavãozinho, logo na primeira dessas reuniões, "o projeto já veio pronto e agora pouco podemos fazer".

Sem a realização dessas reuniões e comissões, a obra física não poderia ser realizada. Dessa maneira, a participação dessas lideranças comunitárias não era apenas um direito, mas acabou tornando-se também um dever a ser cumprido para que o orçamento das obras fosse autorizado. ${ }^{10}$ Lefebvre (1969) chama atenção para o fato de a integração e a participação terem se tornado temas obsedantes, que, na prática, resultariam em uma "integração desintegrante". O autor coloca ainda que a ideologia da participação permite obter pelo menor preço a aquiescência das pessoas interessadas e que estão em questão. Lefebvre formula ainda uma questão que ajuda a pensar a proposta de metodologia participativa formulada pelo PAC e sobretudo a reação das lideranças e moradores diante dela: "Poderá a vida urbana recuperar e intensificar as capacidades de integração e de participação da cidade, quase inteiramente desaparecidas, e que não podem ser estimuladas nem pela via autoritária, nem por prescrição administrativa, nem por intervenção de especialistas?" (Lefebvre, 1969, p. 95).

10 Alguns interessantes trabalhos problematizam a categoria "participação", como o de Simões (1992), por exemplo, que chama atenção para o discurso ideológico de valorização da "participação" no primeiro governo do PT em Diadema (SP), descrevendo como se deu a construção desse ideário participativo. Já a obrigatoriedade da "participação" dos moradores no plano diretor é abordada por Varella (2011). 
Dessa maneira, além desses "canais de participação" oficialmente disponibilizados pelo PAC, quais seriam as estratégias e práticas dos moradores e lideranças para buscar assegurar seus objetivos diante dessa intervenção? A negação em realizar o cadastro e negociar suas casas pode ser pensada como um mecanismo desses moradores para conseguirem pelo menos o reajuste do aluguel social?

Sem negar os mecanismos de reprodução de um modo fragmentado e hierarquizado de integração urbana utilizados pelo PAC, através da descrição etnográfica dessas reuniões, busquei focar a análise também na noção de agência e competência na atuação desses líderes.

A descrição das reuniões do CCOMP buscou destacar a racionalidade da ação dessas lideranças que, conscientes da "participação" que lhes estava sendo proposta, não se ausentaram e entraram em cena, buscando, através de seu engajamento pessoal em cada interação com os membros da equipe do PAC social, levá-los a agir de acordo com suas intenções e objetivos possíveis diante daquele projeto. Críticos e conscientes das limitações de sua "participação" no projeto desde a primeira reunião, tais líderes aceitaram integrar o CCOMP encarando isso como uma das possibilidades existentes dentro de um universo restrito para, através de qualquer possibilidade de margem de manobra, buscar apresentar suas demandas.

Categorias como "gestão participativa", "metodologia participativa" e "participação popular" integram uma gramática política contemporânea, que perpassa os mais diversos movimentos sociais atuais como, por exemplo, o movimento sindical urbano, movimento urbano por moradia, movimento de trabalhadores rurais e movimento indígena. ${ }^{11} \mathrm{O}$ material etnográfico dessas reuniões do PAC social faz pensar que, se por um lado, a participação dos moradores apenas serve para legitimar decisões já tomadas em outras esferas e para reproduzir uma integração hierarquizada e restrita, por outro, lideranças e moradores lutam buscando outros mecanismos e estratégias para assegurar seus objetivos num contexto que sabem ser de possibilidades limitadas. Através de seu engajamento pessoal, esses líderes se mobilizaram, aproveitando toda e qualquer margem de manobra. Concentrar o foco da análise na atuação dessas lideranças

11 Para mais sobre isso, ver Leite Lopes e Heredia (2014). 
em cada situação de negociação não significa negar que as suas conquistas não deixam de ser formas novas dos já antigos mecanismos de "controle negociado", uma vez que seguem assegurando a reprodução do problema favela (Machado da Silva, 2002). A tentativa aqui foi apenas de buscar melhor descrever e analisar em detalhes esse conjunto de ações e as possibilidades de articulação e representação dos moradores e lideranças diante das mesmas.

Tais lideranças e moradores não se colocam o tempo todo contrários à atuação do PAC e do Estado de uma maneira geral. Possuem a competência de saber se aproximar do poder público como "multiplicadores" do projeto para assegurar objetivos específicos, particulares ou não. Sabem, no entanto, também se afastar e posicionar-se contra ele, evidenciando, assim, como as barreiras entre eles são borradas e definem-se contextual ou situacionalmente, como nos ensinou Santos (1981). Mais do que uma ambiguidade na atuação das lideranças do CCOMP, procurei descrever a ambivalência na atuação simultânea dessas lideranças como representantes da comunidade e parceiros do Estado. Ao invés de ressaltar a imprecisão e o que poderia ser tomado como incerto e duvidoso, busquei pensar em como utilizam a seu favor a indeterminação dessa condição, buscando expor demandas e assegurar objetivos em cada interação com os agentes do poder público.

Cefaï, Veiga e Mota (2011), analisando uma série de etnografias da vida associativa, mostram que pesquisas mais recentes recorrem a descrições da ação coletiva que insistem nas múltiplas limitações do campo de ação, na indecisão e na indeterminação das regras do jogo e na ambiguidade das preferências e das motivações. Segundo os autores:

Elas são arenas de troca e de conflito, de cooperação e de competição, de invenção de soluções a problemas, de negociação de convenções coletivas e de composição de racionalidades múltiplas. Estas "anarquias organizadas" não têm um objetivo, uma estratégia e uma ideologia. Elas são atravessadas por ambiguidades e, às vezes, por contradições. Elas podem perseguir diversas finalidades não compatíveis entre si e ser confrontadas com os dilemas da escolha dos meios em relação aos fins. (Cefaï; Veiga; Mota, 2011, p. 35, grifo dos autores).

$\mathrm{O}$ acordo a que se chega entre lideranças e agentes do PAC em uma reunião, em outra ou (frequentemente) na mesma, é facilmente questionado, o mesmo 
dando-se entre as próprias lideranças. É importante destacar a não formação de um "nós" dessas lideranças colocando-se o tempo todo como um grupo unívoco contra o Estado. $\mathrm{O}$ trabalho buscou mostrar que a atuação delas é orientada por múltiplas lógicas e, nessa dinâmica, o Estado pode ser amigo ou inimigo, com quem se produz alianças ou rupturas, dependendo dos interesses em jogo em cada situação. A ação dessas lideranças é orientada assim por uma heterogeneidade dos regimes de ação.

O Estado, por sua vez, não pode também ser pensado como um todo unívoco. Conforme mostramos, esse é formado por agentes que atuam de diferentes formas com os moradores, sendo o tom e a atuação do último engenheiro acima descrito totalmente diferente dos engenheiros anteriores e da equipe de trabalho social. Para concluir, nesse sentido, destacamos ainda intervenções e posicionamentos divergentes do poder público nessas duas favelas vizinhas. Enquanto a Geo-Rio ${ }^{12}$ e a prefeitura delimitavam uma determinada área dessas favelas como "de risco" e marcavam todas as casas que dali deveriam sair, o PAC (governos estadual e federal) construía uma escadaria para dar acessibilidade aos moradores dessa mesma região.

Buscou-se aqui descrever e analisar como essas lideranças com trajetórias, interesses e perspectivas tão distintos atuam, ora competindo, ora cooperando, buscando negociar, produzir acordos e assegurar objetivos nessas arenas públicas. Descrever como se dá a atuação dessas lideranças não significa negar a perversidade da reprodução dos mecanismos de dominação ocultos sob a retórica da "gestão participativa" do PAC. Buscou-se aqui descrever com riqueza de detalhes o processo através do qual essas lideranças tornam públicas nessas arenas as suas demandas, ressaltando a sua competência e a encenação acionada para tal.

12 A Fundação Instituto Geotécnica do Rio de Janeiro (Geo-Rio) é um órgão da Secretaria Municipal de Obras responsável por elaborar estudos e propor soluções de geotecnia para as encostas e áreas de risco da cidade do Rio de Janeiro. Na perspectiva de justificar o "repertório da remoção", em 2009, a prefeitura encomendou um “novo levantamento das chamadas 'áreas de risco' pela Geo-Rio. [...] O mapeamento realizado indicaria que existiriam 17.244 casas em situação de desmoronamento, número bem superior às quase 13 mil moradias apontadas pela listagem de 2009, e que tenderia a crescer, como afirmou o prefeito à época" (Magalhães, 2013, p. 100). 


\section{Referências}

BLASI CUNHA, J. Breves reflexões metodológicas sobre trabalho de campo em uma favela carioca. Terceiro Milênio: Revista Critica de Sociologia Politica, Campo dos Goytacazes, v. 3, n. 2, p. 112-136, 2014a.

BLASI CUNHA, J. "Nossa casaca édupla-face": dinâmica sócio-espacial e política local no processo de implementação do PAC e da UPP em uma favela da cidade do Rio de Janeiro. 2014. Tese (Doutorado em Antropologia Social)-Faculdade de Filosofia, Letras e Ciências Humanas, Universidade de São Paulo, São Paulo, 2014b.

BOLTANSKI, L.; THÉVENOT, L. De la justification. Paris: Gallimard, 1991.

BONDUKI, N. Habitação e autogestão: construindo territórios de utopia. Rio de Janeiro: Fase, 1992.

BONDUKI, N. Os pioneiros da habitação social: volume 1. São Paulo: Ed. Unesp: Edições Sesc São Paulo, 2014.

CAVALCANTI, M. À espera, em ruínas: urbanismo, estética e política no Rio de Janeiro da 'PACificação'. Dilemas, Rio de Janeiro, v. 6, n. 2, p. 191-228, 2013.

CEFAÏ, D.; VEIGA, F.; MOTA, F. Introdução. In: CEFAÏ, D. et al. (Org). Arenas públicas: por uma etnografia da vida associativa. Niterói: Eduff, 2011. p. 9-63.

CERTEAU, M. de. A cultura no plural. Campinas: Papirus, 1995.

COTS: caderno de orientação técnica social: programas setor público. Brasília: Caixa Econômica Federal, 2004.

DAS, V.; POOLE, D. (Ed.). Anthropology in the margins of the state. New Delhi: Oxford University Press, 2004.

ESTADO demolirá 6.408 casas para abras do PAC. O Globo, Rio de Janeiro, 5 mar. 2008. C2, p. 15.

HOLSTON, J. A cidade modernista: uma crítica de Brasília e sua utopia. São Paulo: Companhia das Letras, 1993.

JACOBS, J. Morte e vida das grandes cidades. São Paulo: Martins Fontes, 2007.

LEFEBVRE, H. O direito à cidade. São Paulo: Documentos, 1969.

LEITÃO, G. et al. Barbante, ripas e lutas: ocupações organizadas de terras urbanas no Rio de Janeiro, 1983-1993. Niterói: Eduff, 2016.

LEITE, R. P. Contra-usos da cidade: lugares e espaço público na experiência contemporânea. Campinas: Editora Unicamp; Aracaju: Editora UFS, 2004. 
LEITE LOPES, J. S.; HEREDIA, B. (Org.). Movimentos sociais e esfera pública: o mundo da participação: burocracias, confrontos, aprendizados inesperados. Rio de Janeiro: CEBAE, 2014. Disponível em: <http://www.memov.com.br/site/images/acervo/ MSEP/Mov_Sociais_e_Esfera_Publica_WEB_3.pdf>. Acesso em: 30 jan. 2017.

MACHADO DA SILVA, L. A. A continuidade do problema da favela. In: OLIVEIRA, L. L. (Org.). Cidade: história e desafios. Rio de Janeiro: Editora FGV: CNPq, 2002. p. 220-237.

MAGALHÃES, A. O "legado" dos megaeventos esportivos: a reatualização da remoção de favelas no Rio de Janeiro. Horizontes Antropológicos, Porto Alegre, ano 19, n. 40, p. 89-118, jul./dez. 2013.

RIZEK, C. S.; BARROS, J.; BERGAMIM, M. de A. A política de produção habitacional por mutirões autogeridos: construindo algumas questões. Revista Brasileira de Estudos Urbanos e Regionais, São Paulo, v. 5, n. 1, p. 31-46, maio 2003.

SANTOS, C. N. F. Movimentos urbanos no Rio de Janeiro. Rio de Janeiro: Jorge Zahar, 1981.

SIMÕES, J. A. O dilema da participação popular: a etnografia de um caso. São Paulo: Marco Zero, 1992.

TURNER, J. Vivienda: todo el poder para los usuarios. Madrid: H. Blume, 1977.

VALLADARES, L. do P. A invenção da favela. Rio de Janeiro: FGV, 2005.

VARELLA, A. O dever de cidadania, políticas públicas de planejamento urbano e participação popular no Brasil. In: CEFAÏ, D. et al. (Org). Arenas públicas: por uma etnografia da vida associativa. Niterói: Eduff, 2011. p. 321-348.

VENTURA, Z. Cidade partida. São Paulo: Companhia das Letras, 1994.

VIEIRA DA CUNHA, N.; FELTRAN, G. de S. Sobre periferia: novos conflitos no Brasil contemporâneo. Rio de Janeiro: Lamparina: Fapesp, 2013.

VOGEL, A.; MELLO, M. A.; MOLLICA, O. Quando a rua vira casa. Niterói: Eduff, 2017.

Recebido: 31/01/2017 Aceito: 08/08/2017 | Received: 1/31/2017 Accepted: 8/8/2017 